\title{
ESTUDIOS
}

\section{La Economía y la Psicología ante el problema de la inactividad de las personas con discapacidad}

\author{
Marco Antonio Cruz Morato y Antonio García Lizana'
}

Resumen: La situación laboral de las personas con discapacidad continúa siendo muy negativa, a pesar del creciente interés social por el colectivo. Muchos estudios anteriores coinciden en señalar las bajas tasas de actividad como el principal problema del colectivo en las economías desarrolladas. Sin embargo, una aproximación basada en la Teoría Económica tradicional, en aras a clarificar la situación, deja más interrogantes de los que resuelve. Bajo una perspectiva más amplia, completando el enfoque neoclásico con la teoría institucionalista de los mercados duales de trabajo y analizando la influencia de la discriminación, en este estudio introduciremos elementos tomados de la Psicología (como los procesos de estigmatización o las teorías del estrés) para cubrir las lagunas de dicho análisis, en un contexto de Economía del Comportamiento. Tal modo de proceder nos permitirá ser más precisos en el diseño de medidas de política económica que busquen atajar el problema.

Palabras clave: Discapacidad, Economía del comportamiento, estigma, estrés, mercado laboral.

Fecha de recepción: 21 de febrero de 2011.

Fecha de aceptación definitiva: 4 de julio de $201 \mathrm{I}$.

\footnotetext{
' Departamento de Economía Aplicada (Política Económica), Universidad de Málaga
} 


\section{Economy and Psychology with res- pect to the problema of inactivity in the handicapped}

\begin{abstract}
The employment situation of those with disabilities is still very negative, despite increasing social interest in this sector. Many previous studies coincide in pointing to low rates of activity as the main problem this group encounters in industrialised economies. However, an approach based on traditional Economic Theory, in an effort to clarify the situation, poses more questions than it answers. From a broader view point complementing a neoclassical approach with the institutionalist theory of dual work markets and analyzing the influence of discrimination, this paper introduces elements drawn from Psychology (like processes involving stigmas and theories of stress) to bridge some gaps in this analysis, in a context of Behavioural Economics. This plan of action will allow us to be more precise in designing measures of economic policy to tackle the root of this problem.
\end{abstract}

Key words: Handicapped, disabilities, Behavioural Economics, stigma, stress, work market.

\section{L'Économie et la Psychologie face à l'inactivité des personnes handicapées}

Résumé: Le statut des personnes handicapées dans le monde de l'emploi continue à être très négatif, malgré l'intérêt social croissant pour ce collectif. Beaucoup d'études précédentes ont montré que le problème principal pour ce collectifdans les économies développées est leur faible taux d'activité. Cependant, une approche basée sur la Théorie Économique traditionnelle, dans le but de clarifier la situation, pose plus de questions qu'elle n'en résout. Sous une perspective plus large, en complétant l'approche néoclassique avec la théorie institutionnaliste des doubles marchés du travail et en analysant l'influence de la discrimination, nous allons introduire dans cet article des éléments pris de la Psychologie (comme les aspects de la stigmatisation ou les théories du stress) afin de subvenir aux manques de cet analyse, dans le contexte de l'Economie du Comportement. De cette façon nous pourrons être plus précis dans la conception de nouvelles mesures de politique économique afin de résoudre le problème.

Mots clés: Handicap, Économie du Comportement, stigmatisation, stress, marché du travail.

\section{Introducción}

De los problemas detectados en la vida cotidiana de las personas con discapacidad (PCD), merece especial atención la desfavorable situación laboral del colectivo. El trabajo no sólo supone una fuente de ingresos, a menudo imprescindible para la supervivencia del individuo y su familia; el trabajo supone también la realización del individuo, su crecimiento personal y una vía de integración en la sociedad. 
En J. A. Rodríguez y J. Delgado (2009) podemos encontrar un análisis de la atención a la integración laboral de las PCD por parte de las instituciones de la Unión Europea.

Diversos estudios coinciden en destacar las bajas tasas de actividad como el principal problema laboral de las PCD en las economías desarrolladas. En este sentido pueden citarse, por ejemplo, C. García Serrano y M. A. Malo (2002), B. Gannon y B. Nolan, (2004) y (2007), M. R. Vicente y A. J. López (2007), OCDE (2007), I. Albarrán y otros (2009), A. García Lizana y C. Cazallas Alcaide (2009), etc. Según los primeros (p. 249): el principal problema de las personas discapacitadas es la entrada en la población activa (su baja tasa de actividad) más que la dificultad de encontrar empleo (aunque este problema también puede existir). Los datos de la OCDE (2007) no sólo indican que la inactividad en las PCD es muy alta, sino que además exponen que a un alto porcentaje de personas inactivas les gustaría tener un trabajo remunerado². Se muestra así una disfunción en el mercado laboral de las PCD; algo debe estar ocurriendo para que las personas "inactivas" deseen trabajar y no sean consideradas como personas paradas (de acuerdo con la definición de las estadísticas laborales utilizadas parecería lo más lógico). Según A. LiTtE no hay duda de que muchos individuos con problemas de salud de larga duración son capaces de volver a alguna forma de empleo, o que a un número significativo le gustaría volver a trabajar ${ }^{3}$. ¿Por qué permanecen en la inactividad, pues? De acuerdo con este autor, estos "desempleados ocultos" deberían formar parte de la oferta laboral.

El objetivo de este artículo es contribuir a la búsqueda de posibles respuestas al problema de la escasa participación de las PCD en el mercado laboral, introduciendo una perspectiva psicológica en el análisis económico para completar las lagunas que el mismo presenta. Por tanto, se seguirá una perspectiva cercana a la Economía del Comportamiento ( $\mathrm{EdC})$, un campo donde se buscan explicaciones a fenómenos económicos recurriendo a teorías psicológicas para ser integradas en el propio análisis económico, pero, conviene advertirlo, sin renunciar a las posibilidades abiertas por otras escuelas de pensamiento, con el propósito de abordar más sólidamente un problema lleno de dificultades de interpretación, de

\footnotetext{
2 De esta manera, por recoger algunos datos relevantes, el porcentaje de personas inactivas con una discapacidad permanente que declaran desear incorporarse al mercado laboral, en el periodo 2004-2005, sería del 14,4\% en España, y del 45,1\% en Reino Unido, siendo la media de los países europeos pertenecientes a la OCDE del 20,9\% (ver OCDE 2007).
}

${ }^{3}$ A. LITTLE (2007), 51 
manera que ello facilite el diseño de aplicaciones políiticas capaces de mejorar la situación.

El artículo está organizado como sigue: en el apartado 2 se recogen algunos datos que permitan apreciar la situación laboral de las $\mathrm{PCD}$, en relación con el resto de la población; en el apartado 3 se aborda la explicación teórica del problema, señalando las cuestiones que la Teoría Económica tradicional deja sin explicar, la utilidad de recurrir a la Psicología, y cómo todo esto nos lleva a un contexto de EdC; en el apartado 4, situados en dicho marco teórico, introducimos diversas teorías psicológicas (como los procesos de estigmatización y las teorías del estrés), para explicar la escasa participación laboral de las PCD; en el apartado 5 apuntaremos algunas aplicaciones de política económica que pueden extraerse del estudio anterior; para finalizar, en el último apartado, presentamos las conclusiones de nuestro análisis.

\section{Una aproximación empírica a la situación laboral de las per- sonas con discapacidad}

Como se ha apuntado en la introducción, diversos autores se han ocupado del problema de la baja tasa de actividad de las PCD. Así, M. R. Vicente y A. J. López advierten que en el conjunto de la Unión [Europea] el $45 \%$ de las personas con discapacidad es económicamente inactivo, frente a un $26,6 \%$ de los no discapacitados $^{4}$. Como es fácil de apreciar, y así lo hacen los autores, tales cifras revelan un importante potencial desaprovechado para el crecimiento económico. B. Gannon y B. Nolan ${ }^{5}$, por su parte, analizan la situación irlandesa, relacionando la discapacidad con un decremento de 20 puntos porcentuales en la probabilidad de ser activo.

Del caso español se han ocupado I. Albarrán y otros (2009), utilizando datos tomados de la Encuesta de Discapacidades, Deficiencias y Estados de Salud (1999) (ver INE, 2002), según la cual la tasa de actividad de las PCD de ambos sexos se situaría en el 32,1\%, mientras que para el conjunto de la población alcanzaría el $65,5 \%$, datos que se verían corroborados en 2002 en el Módulo específico para "Las personas con discapacidad y su relación con el empleo" de la EPA, según recogen A. García Lizana y C. Cazallas Alcaide, tal como se presentan en la Tabla 1.

${ }^{4}$ M. R. VICENTE Y A. J. LóPEZ (2007), 432.

${ }^{5}$ B. Gannon (2004) y B. Nolan (2007). 
TABLA I: Tasas de actividad, ocupación y desempleo de personas con y sin discapacidad

\begin{tabular}{|l|l|c|c|c|}
\hline Colectivos & \multicolumn{1}{|c|}{ Tasas } & Ambos sexos & Varones & Mujeres \\
\hline \multirow{2}{*}{$\begin{array}{l}\text { Personas Con } \\
\text { Discapacidad }\end{array}$} & Tasa de actividad & $\mathbf{3 3 , 7}$ & $\mathbf{3 9 , 3}$ & $\mathbf{2 7 , 1}$ \\
\cline { 2 - 5 } & Tasa de empleo & $\mathbf{2 8 , 5}$ & $\mathbf{3 4 , 3}$ & $\mathbf{2 1 , 7}$ \\
\cline { 2 - 5 } & Tasa de paro & $\mathbf{1 5 , 3}$ & $\mathbf{1 2 , 8}$ & $\mathbf{1 9 , 7}$ \\
\hline \multirow{2}{*}{$\begin{array}{l}\text { Personas Sin } \\
\text { Discapacidad }\end{array}$} & Tasa de actividad & $\mathbf{7 0 , 0}$ & $\mathbf{8 4 , 4}$ & $\mathbf{5 5 , 8}$ \\
\cline { 2 - 5 } & Tasa de empleo & $\mathbf{6 2 , 4}$ & $\mathbf{7 8 , 1}$ & $\mathbf{4 8 , 7}$ \\
\cline { 2 - 5 } & Tasa de paro & $\mathbf{1 1 , 0}$ & $\mathbf{7 , 5}$ & $\mathbf{1 6 , 2}$ \\
\hline
\end{tabular}

Fuente: García lizana, A. y Cazallas Alcaide, C. (2009), a partir de Instituto Nacional de Estadística: Encuesta de población Activa. Módulo de 2002.

Como fácilmente puede comprobarse, la situación de las PCD (para ambos sexos) presenta rasgos que las distancian de las personas sin discapacidad: las tasas de actividad y ocupación son menores, mientras que las de paro son más elevadas. Igualmente, la situación de las mujeres dentro del grupo de PCD es más desfavorable (en los aspectos indicados) que la de los varones. Pero obsérvese que tanto en el caso de los varones como en el de las mujeres, la diferencia con las personas sin discapacidad no es demasiado relevante en el caso del desempleo, sino en la tasa de actividad (si la diferencia en la tasa de ocupación resulta elevada es por la influencia sobre la misma de la tasa de actividad).

\section{Cómo explicar el problema}

\section{I. Puntos débiles de la Teoría Económica tradicional}

Para poder explicar el fenómeno de las bajas tasas de actividad del colectivo de PCD, comenzaremos exponiendo, de forma muy esquemática, la explicación proporcionada por la Teoría Económica convencional al respecto. De esta forma, atendiendo a las características del fenómeno estudiado, lo más apropiado es recurrir al análisis microeconómico, ya que en definitiva se trata de estudiar el comportamiento ante el trabajo de las PCD y de cómo sus decisiones individuales condicionarán la oferta laboral del colectivo. 
Dicho lo anterior, y siguiendo a A. García Lizana y C. Cazallas Alcaide (2009), partiremos de la aproximación neoclásica, según la cual, el mercado laboral es considerado un caso particular del modelo de equilibrio general walrasiano. Oferta y demanda laboral se van ajustando hasta alcanzar el punto de equilibrio, en un contexto bajo los supuestos de flexibilidad de precios y competencia perfecta. La determinación de la oferta laboral del individuo vendrá del proceso de optimización de sus preferencias psicológicas entre ocio y consumo (representadas por las curvas de indiferencia), sujetos a una restricción presupuestaria (lo que el individuo consume no puede ser superior a sus disponibilidades de recursos, tanto salariales como no salariales), en un marco de teoría de elección del consumidor. Por tanto: las personas van a decidir el número de horas que desean trabajar en función del salario, estando condicionadas en el largo plazo por las rentas no salariales y sus preferencias psicológicas ${ }^{6}$.

Según C. McConnell, S. Brue y D. MacPherson (2003), el modelo básico del trabajo y el ocio puede ser muy útil para explicar la inactividad. Esto es así ya que dicho modelo analiza las decisiones individuales sobre la asignación del tiempo entre ocio y trabajo, que condicionarán la oferta laboral. Una situación de inactividad, en la medida en que supone una preferencia por el ocio (es decir, por quedarse fuera del mercado laboral, sea por razones domésticas, de estudios, etc.), conlleva una retracción de la curva de oferta laboral por debajo de su nivel potencial. Un ejemplo característico que podría aducirse es el representado por la población femenina, como puede verse en la tabla 2, a partir de las cifras proporcionadas por la Encuesta de Población Activa del tercer trimestre de 2010 (ver INSTITUTO NACIONAL de Estadística, 2011).

TABLA 2: Tasas de actividad, ocupación y desempleo por sexo

\begin{tabular}{|l|c|c|c|}
\hline \multicolumn{1}{|c|}{ Tasas } & $\begin{array}{c}\text { Ambos } \\
\text { sexos }\end{array}$ & Varones & Mujeres \\
\hline Tasa de actividad & $\mathbf{6 0 , 1}$ & $\mathbf{6 8 , 3}$ & $\mathbf{5 2 , 2}$ \\
\hline Tasa de empleo & $\mathbf{4 8 , 2}$ & $\mathbf{5 5 , 1}$ & $\mathbf{4 8 , 6}$ \\
\hline Tasa de paro & $\mathbf{1 9 , 8}$ & $\mathbf{1 9 , 3}$ & $\mathbf{2 0 , 4}$ \\
\hline
\end{tabular}

Fuente: InStituto NACIONAL DE Estadística (2011).

Elaboración propia.

${ }^{6}$ A. García lizana y C. Cazallas Alcaide (2009), 6 
En efecto, la tasa de actividad femenina es sensiblemente inferior a la del varón, lo que, por el criterio aquí señalado, podría explicarse por la preponderante dedicación de la mujer a las tareas del hogar, de acuerdo con los usos tradicionales. Algo análogo podría concluirse si observamos el comportamiento de acuerdo con la edad de los sujetos (ver figura 1). La menor actividad durante la etapa juvenil vendría explicada por las preferencias por la formación frente al trabajo. En cuanto a las cifras correspondientes a los mayores de 55 años, conviene advertir la presencia entre los mismos de la población jubilada, que distorsiona la interpretación de las cifras. En el caso de la población femenina por tramos de edad se estarían acumulando ambas tendencias.

\section{FIGURA I: Tasa de actividad, ocupación y desempleo por sexo y edad}

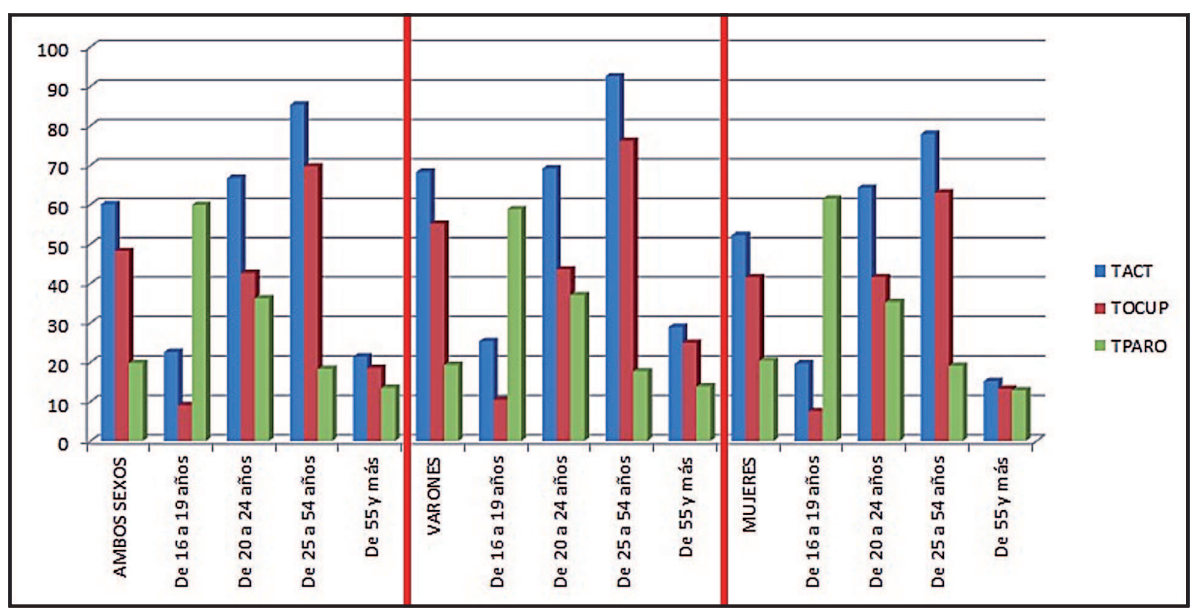

Fuente: Instituto Nacional de Estadística (2011).

Elaboración propia.

Como contrapunto, resulta del mayor interés la situación comparada de la población inmigrante, tal y como puede verse en la Tabla 3. Obviamente, al producirse la corriente migratoria bajo el estímulo de mejorar la situación personal accediendo a un mercado de trabajo inexistente o muy deficiente en el país de origen, las preferencias de los individuos se decantan claramente por el trabajo (sin olvidar que la migración se concentra fundamentalmente en los tramos centrales de edad, en los que las preferencias laborales serían mayores, como acabamos de considerar). 
TABLA 3: Tasas de actividad, ocupación y desempleo por lugar de procedencia

\begin{tabular}{|l|l|c|c|c|}
\hline Colectivos & \multicolumn{1}{|c|}{ Tasas } & Ambos sexos & Varones & Mujeres \\
\hline \multirow{2}{*}{$\begin{array}{l}\text { Población } \\
\text { extranjera }\end{array}$} & Tasa de actividad & $\mathbf{7 7 , 2}$ & $\mathbf{8 4 , 5}$ & $\mathbf{7 0 , 3}$ \\
\cline { 2 - 5 } & Tasa de empleo & $\mathbf{5 4 , 6}$ & $\mathbf{5 8 , 4}$ & $\mathbf{5 0 , 9}$ \\
\cline { 2 - 5 } & Tasa de paro & $\mathbf{2 9 , 3}$ & $\mathbf{3 0 , 9}$ & $\mathbf{2 7 , 5}$ \\
\hline \multirow{3}{*}{$\begin{array}{l}\text { Población } \\
\text { española }\end{array}$} & Tasa de actividad & $\mathbf{5 7 , 7}$ & $\mathbf{6 6 , 0}$ & $\mathbf{4 9 , 7}$ \\
\cline { 2 - 5 } & Tasa de empleo & $\mathbf{4 7 , 3}$ & $\mathbf{5 4 , 6}$ & $\mathbf{4 0 , 2}$ \\
\cline { 2 - 5 } & Tasa de paro & $\mathbf{1 8 , 0}$ & $\mathbf{1 7 , 2}$ & $\mathbf{1 9 , 0}$ \\
\hline
\end{tabular}

Fuente: Instituto Nacional de Estadística (2011).

Elaboración propia.

Para verlo con mayor claridad, se ha venido recurriendo al concepto de salario de reserva (el salario mínimo por el que un individuo decide trabajar, pues recibe los incentivos adecuados). Un salario de reserva muy elevado implica una mayor valoración del ocio. De esta forma, la menor participación de las PCD en el mercado laboral vendría explicada por la existencia de un salario de reserva superior al salario de equilibrio del mercado. Este salario de reserva tan elevado sería consecuencia de las preferencias psicológicas subjetivas del individuo (influenciadas por motivaciones como los usos sociales; los mayores costes personales, en términos monetarios o de esfuerzo, para acceder al mercado laboral y para ocupar el puesto de trabajo; las necesidades temporales para atención médica y rehabilitación, etc.) y de la existencia de otras fuentes de ingresos alternativas. Según A. Little,

las personas con discapacidad que no tienen trabajo pueden recibir prestaciones de la seguridad social más altas que las disponibles para desempleados, aumentando así su salario de reserva ${ }^{7}$.

Obviamente, análogos criterios podrían plantearse en el caso de la población femenina (aunque con menos intensidad) o de la comprendida en los tramos extremos de edad; mientras que la mayor actividad de la población inmigrante vendría justificada por la existencia de un salario de reserva más reducido.

No obstante, el modelo tradicional puede ser criticable, por lo que aquí interesa,

${ }^{7}$ A. LITLE (2007), 51 
en un aspecto. Al partir del análisis microeconómico, considerando la existencia de un agente económico individual representativo, el modelo tradicional supone la existencia de una fuerza laboral homogénea que responde a similares motivaciones, matizadas de la forma dicha. Sin embargo, como indican M. R. Vicente y A. J. López ${ }^{8}$ conviene tener presente que las personas con discapacidad no constituyen un grupo homogéneo?

Así pues, en la realidad se observan una serie de contradicciones que inducen a pensar que existe una variedad de comportamientos. Partamos del hecho de que las PCD desean maximizar su utilidad. Si observamos los esfuerzos por la integración que vienen demostrando ${ }^{10}$, la maximización de su utilidad vendría con la participación en el mercado laboral. Entonces, ¿̇es consistente la afirmación de que mantienen un salario de reserva elevado? Pero si admitimos que el salario de reserva es más elevado, parecería que la maximización de la utilidad estuviera asociada con la inactividad. En este caso, ¿̇por qué el colectivo se esfuerza por integrarse? Existe pues una contradicción, o algún elemento ha quedado fuera del análisis. Puede que el salario de reserva no sea para todas las PCD más elevado que el salario de equilibrio del mercado o que sea preciso buscar otras líneas de interpretación del problema.

Para intentar explicar esta situación, y atendiendo a que los dos enfoques más aceptados en este terreno [son] las teorías neoclásicas e institucionalistas ${ }^{11}$, haremos

\footnotetext{
${ }^{8}$ M. R. VICENTE Y A. J. LÓPEZ (2007), 432.
}

9 No obstante, en orden a encontrar una explicación consistente, habría que tener en cuenta que es especialmente tentador [...] el uso de la heterogeneidad de preferencias para explicar los comportamientos (H. BENíreZ-SIIVA (2009) 192). De lo que se trata en este artículo es de identificar patrones de conducta homogéneos en grupos distintos dentro de un colectivo heterogéneo, sin caer en la argumentación demagógica de la heterogeneidad como excusa para refutar una determinada teoría.

10 Basta tener en cuenta las numerosas iniciativas promovidas por las organizaciones de PCD existentes en nuestro país (COCEMFE, PREDIF, ONCE, CNSE, etc.), y, en particular, por el Comité Español de Representantes de Personas con Discapacidad (CERMI), que agrupa al conjunto de asociaciones y fundaciones (más de 4000 entidades) vinculadas con dicha población. Así, podríamos citar la "Estrategia Global de Acción para el Empleo de las Personas con Discapacidad 2008-2012", aprobada por el Gobierno en 2008, a propuesta del CERMI, en el marco de la Ley de Integración Social de los Minusválidos (LISMI).

$"$ A. García lizana y C. Cazallas Alcaide (2009), 5. 
referencia a la teoría institucionalista de los mercados duales de trabajo. Como crítica a la visión neoclásica, esta teoría supone la existencia de dos segmentos en el mercado laboral, con características contrapuestas. Por una parte encontramos el mercado primario, en el que las condiciones laborales y salariales son muy buenas. Por otra parte, existe un mercado secundario en el que dichas condiciones son mucho más precarias ${ }^{12}$. Es un lugar común la inclusión en el mercado secundario de los grupos de población específicos a que nos venimos refiriendo, como inmigrantes, población femenina o joven. $Y$, por supuesto, todas las $P C D^{13}$. Las menores tasas de actividad y las mayores tasas de desempleo que aparecen en los datos presentados se convertirían en indicadores de tal situación.

Sin embargo, atendiendo a la evidencia empírica, también encontramos indicios sobre el comportamiento en el mercado laboral de las PCD que nos sugieren una situación más matizada, advirtiéndose una asimetría dentro de dicha población, con segmentos muy diferenciados. Hasta el punto de coexistir junto al importante número de inactivos y desempleados, y de empleados en situación precaria, un significativo conjunto de PCD bien situadas, que incluso presentan datos más positivos que los ofrecidos por el total de la población.

Así, a título de ejemplo, se podría hacer referencia al tipo de contratos realizados: para el conjunto del mercado, el porcentaje medio de contratos indefinidos firmados durante el periodo de enero de 2006 a julio de 2008, de acuerdo con los datos ofrecidos por el Instituto Nacional de Empleo (INEM), fue del 11,9\%, mientras que en el caso de los minusválidos (empleados en el segmento de mercado no protegido) este porcentaje se elevó hasta el $43,3 \%$. Además, la formación media de los minusválidos contratados en el segmento no protegido es superior a la media del mercado, en particular entre los varones; así, en torno al $85 \%$ de los discapacitados contratados varones ha finalizado al menos la enseñanza secundaria, mientras que ello sólo ocurre en torno a un $75 \%$ del conjunto de los varones contratados; la diferencia es menor en el caso de las mujeres (ver INEM 2006-2008).

De esta forma, existiría un segmento de trabajadores discapacitados con buenos niveles formativos y bien situados en el mercado de trabajo (a los que habría que ubicar, por tanto, en el mercado primario), frente a un subgrupo más numeroso de $P C D$, que estarían en el mercado secundario.

12 P. DOERINGER Y M. PIORE (1985)

${ }^{13}$ Véase D. HAGNER (2000) 
No obstante, hemos de decir que el enfoque institucionalista aplicado a las PCD también es criticable en un aspecto, ya que para éste los integrantes del mercado secundario estarían dispuestos a aceptar salarios más bajos que el resto, cosa que parece no ocurrir, ya que las PCD permanecen mayoritariamente en la inactividad. Lo que podría hacernos pensar, nuevamente, en la existencia de un salario de reserva superior al salario de equilibrio del mercado secundario, por lo que no están dispuestos a aceptarlo; lo que afecta, en definitiva, a su función de oferta laboral, haciéndola más rígida y desplazándola hacia la izquierda, manteniéndose en la inactividad. O bien, ¿̇podría darse el caso de un tercer grupo, o, más bien, de dos subgrupos distintos dentro del mercado secundario, con salarios de reserva diferentes: uno que prefiriera la inactividad ante el bajo salario de equilibrio del mercado, y otro, con un salario de reserva menor, que admitiera las peores condiciones de empleo del mercado secundario? Y si esto fuese así, żqué habría detrás de esta situación?

Si admitimos, por tanto, la existencia de comportamientos diferentes por parte de los oferentes de mano de obra, que matizan su inserción en los mercados primario y secundario, parece pertinente retomar el hilo inicial del discurso, para considerar cómo la oferta laboral del individuo se desprende del proceso de optimización de sus preferencias psicológicas entre ocio y consumo, coordinando, en este sentido, las aportaciones de las dos escuelas consideradas.

De acuerdo con ello, y como puede verse en las figuras 2 y 3 , la clave estaría en las preferencias psicológicas subjetivas del individuo, representadas por las curvas de indiferencia, así como en las rentas no salariales percibidas por las PCD, confrontadas con la existencia de un mercado laboral segmentado.

En efecto, basándonos en un gráfico utilizado por C. McConnell, S. Brue y D. MacPherson (2003) para explicar la inactividad de los beneficiarios de pensiones por jubilación, hemos adaptado la situación para representar la problemática estudiada en las PCD. Así pues, en la figura 2 podemos observar una serie de características. En primer lugar, las curvas de indiferencia del individuo discapacitado ( $a$, b y $\mathrm{c}$ ) son muy inclinadas, lo que indica que sus preferencias psicológicas subjetivas conceden más valor al ocio (o menos valor al trabajo, entre otras razones, por la penalidad que supone la búsqueda de empleo y el trabajo en sí, en un contexto en el que existen barreras que lo limitan). La recta horizontal $N^{\prime} N^{\prime}$ representa la restricción presupuestaria del individuo en el caso de recibir la prestación por discapacidad HN (y no participar en la población activa). Para una persona con discapacidad del mercado secundario, la restricción presupuestaria si participase en la población activa estaría recogida en la recta WH. De esta forma, comparando los puntos A y 
$\mathrm{N}$, vemos como el individuo obtiene una mayor utilidad en $\mathrm{N}$ (puesto que la curva de indiferencia $b$ se encuentra más alejada del origen que la curva de indiferencia a), es decir, el individuo obtiene mayor utilidad con la inactividad, dedicando las 24 horas del día al ocio (dada la existencia de la prestación por discapacidad $\mathrm{HN}$ y la forma de las curvas de indiferencia).

\section{FIGURA 2: Inactividad, participación y mercado dual de trabajo}

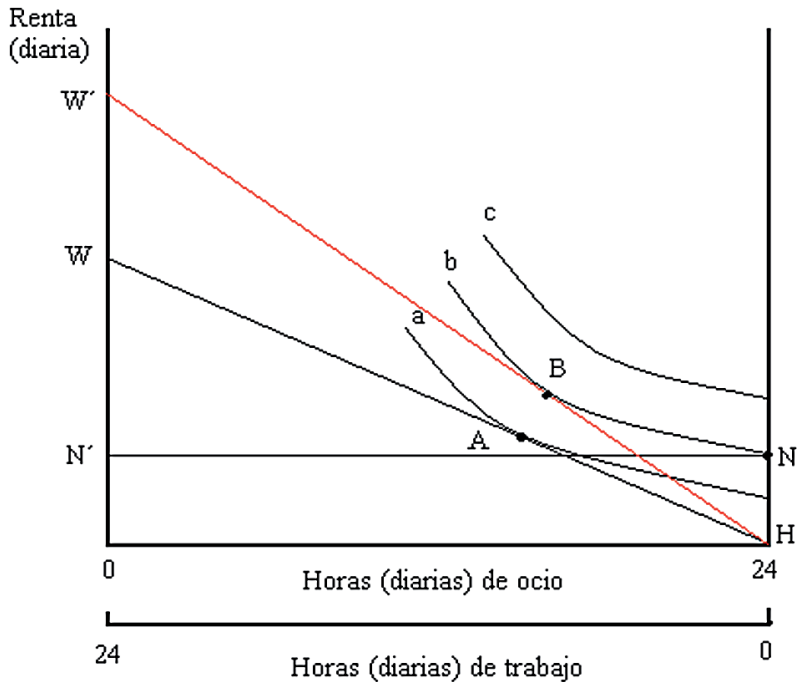

Fuente: C. MCCONNELL, S. BRUE Y D. MACPHERSON (2003).

Elaboración propia.

Por el contrario, si la restricción presupuestaria estuviera representada por $\mathrm{W}^{\prime} \mathrm{H}$ (siendo el salario $\mathrm{W}^{\prime}$ mayor que el salario $\mathrm{W}$, un incremento salarial que suele ocurrir al pasar del mercado secundario al primario), el punto de corte con la curva de indiferencia $b$ se produciría en $\mathrm{B}$. Comparando los puntos $\mathrm{B}$ y $\mathrm{N}$ vemos que existe indiferencia entre ambos (mismo nivel de utilidad representado por la curva de indiferencia b). De esta forma, por encima del salario $W^{\prime}$, el individuo preferiría participar en la población activa, promoviéndose la integración laboral. Es decir, W' sería el salario de reserva de las PCD, bajo el supuesto de este tipo de curvas de indiferencia y la existencia de la prestación HN. Suponiendo análogas curvas de indiferencia para todas las PCD, el salario de reserva sería el mismo, tanto para las personas del mercado primario como para las del secundario. Lo único que ocurriría es que presumiblemente sería mayor que el salario de equilibrio 
para las personas del mercado secundario (provocando la preferencia de éstos por la inactividad), mientras que sería igual o inferior para las del mercado primario, incentivando así la participación laboral de las personas con posibilidades de acceder a dicho mercado primario, según la forma de las curvas representadas.

Para una PCD del mercado primario, si cambiasen sus preferencias psicológicas individuales (lo que puede ser razonable de asumir, por la satisfacción que puede acompañar el ejercicio de un trabajo más cualificado o más valorado socialmente) y se representasen por un mapa de curvas de indiferencia donde éstas fuesen menos inclinadas, la situación sería aún más favorable (para análogo nivel salarial de mercado), ya que al individuo le reportaría mayor utilidad la participación en el mercado laboral (ahora le tentaría menos la idea de ser inactivo, pues no existiría una curva de indiferencia tal que pasase simultáneamente por los puntos $\mathrm{B}$ y $\mathrm{N}$; la curva de indiferencia que pasaría por el punto $\mathrm{N}$ sería inferior a la que correspondería al actual punto B).

Sin embargo, una modificación similar de preferencias en las personas del mercado secundario podría traducirse en un impacto aún más significativo, en términos de actividad laboral. Así pues, en la figura 3 podemos ver cómo la forma de las curvas de indiferencia es un aspecto clave en la decisión sobre inactividad o integración laboral. Frente a las curvas de indiferencia a, b y c, (muy inclinadas) anteriormente vistas, si el individuo discapacitado del mercado secundario tuviese otras preferencias psicológicas subjetivas que se vieran representadas por las curvas $a^{\prime}, b^{\prime}$ y $c^{\prime}$ (más planas, debido a que la búsqueda de empleo y el trabajo en sí no le suponen tanta penalidad, a pesar de la existencia de barreras que limitan el empleo; o le resulta más atractivo el hecho de tener un empleo, sea por motivos personales, familiares o de integración social, etc.), la maximización de la utilidad se conseguiría, ahora, en el punto $C$ y no en el punto $\mathrm{N}$, para el mismo salario W. Es decir, la PCD optaría por la participación en el mercado laboral como forma de maximizar su utilidad (abandonando la inactividad), con un salario de reserva inferior a $W^{\prime}$ (e incluso inferior a W).

Obviamente, en la práctica, pueden existir posiciones aún más matizadas, que arrojarían un espectro sociolaboral bastante más diversificado, lo que cuestiona, ciertamente, la asunción convencional de interpretar el empleo de las PCD de una manera homogénea y uniforme. Los dos mapas de curvas de indiferencia representados muestran perfiles laborales diferenciados entre las $P C D$, que conviene tener presentes para una adecuada comprensión del problema que nos ocupa. 


\section{FIGURA 3: Preferencias psicológicas subjetivas y subgrupos en el mercado secundario}

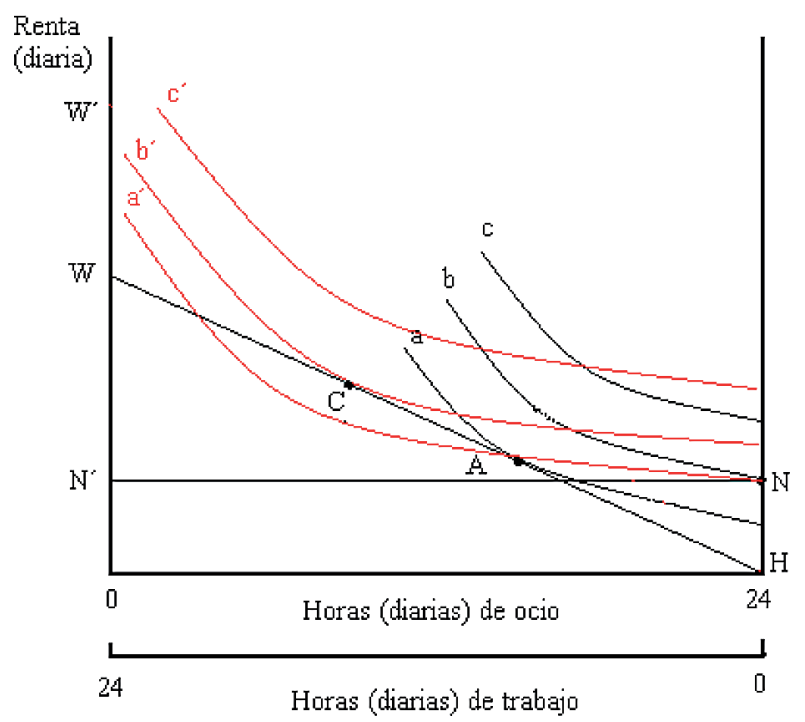

Fuente: C. McConnelL, S. BRUe y D. MACPHERSON (2003).

Elaboración propia.

Sea como sea, y en todo caso, puede afirmarse siguiendo a C. McConnell, S. Brue Y D. MacPherson (2003), que cuanto menor sea el salario de equilibrio del mercado, más probable es que el individuo no participe en la población activa. Un salario reducido permite cubrir con mayor dificultad las aspiraciones de las PCD en términos de salario de reserva, dado un determinado nivel de rentas no salariales (sean de origen familiar o asistencial, tanto público como privado). En tales circunstancias, aumenta la probabilidad de que un individuo forme parte del subgrupo del mercado secundario que prefiere la inactividad. Sólo accediendo al mercado primario se conseguirían salarios suficientemente elevados para estimular la actividad de una manera más amplia. Sin embargo, el problema reside en que la mayoría de las PCD parecen tener cerradas las puertas del mercado primario, por una menor dotación de capital humano, por los prejuicios existentes, etc., lo que explicaría las reducidas tasas de participación en el mercado laboral, pudiendo concluir, en consecuencia, coincidiendo con D. Hagner (2000), que el paso del mercado secundario hacia el primario es un aspecto fundamental para las PCD.

De esta manera, podríamos explicar las contradicciones observadas anteriormente, vinculando a los integrantes del mercado primario con los esfuerzos por la inte- 
gración y a los del secundario con la inactividad (mayoritariamente, sin perjuicio de la posible existencia de subgrupos en el mercado secundario), como forma de maximizar la utilidad.

Pero no es esto todo. La cuestión importante, desde un punto de vista pragmático, es poder determinar la mayor o menor rigidez de las preferencias de las personas presumiblemente situadas en el mercado secundario, cuando nos enfrentamos con las altas tasas de inactividad actuales. Presumiblemente, sus funciones de indiferencia parecen ser bastante inclinadas; asunto éste sobre el que habría que profundizar.

A. Little apostilla que, con independencia de la percepción de rentas no salariales,

los demandantes de beneficios por incapacidad también perciben la existencia de barreras al empleo, como la discriminación del empleador [...] Consecuentemente, incluso aunque expresen que les gustaría trabajar, esto no implica necesariamente que están lo suficientemente motivados para reincorporarse a la fuerza laboral, en vista de estas barreras. $^{14}$

Es decir, las PCD pueden desear incorporarse a la población activa (incluso las del mercado secundario); pero dado que perciben la existencia de una serie de barreras al empleo (lo que desde una perspectiva económica se puede traducir como un coste adicional) sus preferencias psicológicas individuales se verán afectadas, aumentando la rigidez de su función de utilidad, lo que para un nivel de renta no salarial dado tiene como resultado mantener el salario de reserva en un nivel muy elevado, produciendo que la maximización de la utilidad se identifique con la permanencia en la inactividad.

Ahora bien, ¿qué puede ocurrir si las barreras al empleo señaladas anteriormente por Little están actuando tan fuerte y persistentemente que las pendientes de las curvas de utilidad se aproximan a infinito? En tales circunstancias, está claro que las preferencias de los sujetos se inclinan claramente por la inactividad, forzando el salario de reserva hacia un valor arbitrariamente elevado, lo que lo convierte en un elemento claramente disuasorio. Si esto ocurre, habría que admitir que el comportamiento de la oferta laboral de las PCD se hace independiente del nivel salarial, al mismo tiempo que se desplaza sensiblemente hacia la izquierda, reduciéndose en consecuencia la tasa de actividad. La frustración, o el desánimo provocados por las barreras pueden generar un nivel de expectativas suficientemente negativo

${ }^{14}$ A. LITLE (2007), 51. 
como para eliminar cualquier búsqueda de empleo, rompiendo la relación entre oferta y nivel de retribución ${ }^{15}$.

C. Barnes y G. Mercer (2005) son, también, de análoga opinión. El colectivo de PCD se encuentra excluido del entorno laboral debido a la existencia de barreras, tanto sociales como ambientales. A. García Lizana y C. Cazallas Alcaide (2009) hablan de barreras psicosociales, matizando que las mismas afectan tanto a la oferta como a la demanda laboral del colectivo. J. Edwards y K. Boxall (2010) también tratan el asunto de las barreras al empleo (aunque centrándose en los adultos con fibrosis quística). Por su parte, J. Barlow, C. Wright y L. Cullen (2002), citando a M. Hirst y S. Baldwin (1994), y T. Kroll y S. Peake (1996), exponen que una serie de barreras internas y externas hacen que las $\mathrm{PCD}$ estén en mayor riesgo de desempleo. Citando a J. H. Barlow (1998), señalan que las barreras internas están relacionadas con la existencia de limitaciones físicas, incertidumbre, necesidad de tratamiento y vulnerabilidad al estrés psicológico ${ }^{16}$. Las barreras externas podrían, a su vez, de acuerdo con los referidos J. Barlow, C. Wright, y L. Cullen, y citando en esta ocasión a J.H. Barlow y K. Harrison (1996), agruparse en ambientales, por procedimientos administrativos y por actitudes de la sociedad.

Refiriéndonos a las barreras ambientales destacaríamos las relativas a la accesibilidad de los entornos físicos. Las barreras por procedimientos administrativos nos permiten conectar de nuevo con las teorías institucionalistas de los mercados internos y duales de trabajo ${ }^{17}$. Según la primera, las empresas mantienen relaciones estables con los trabajadores, fijándose los salarios mediante diversos procedimientos administrativos, y cubriéndose muchos puestos por promoción interna (en lugar de cubrirse por medio de la búsqueda de candidatos externos, mediante los procedimientos neoclásicos de oferta y demanda de trabajo), a través de procesos institucionalizados. De esta forma, existirá una barrera al empleo en el sentido de que, si se tiende a perpetuar la selección inicial de trabajadores realizada por la empresa, dado que puede existir alguna desigualdad en la contratación de PCD, la misma tenderá a mantenerse indefinidamente ${ }^{18}$.

${ }^{15}$ Ver A. García lizana y C.Cazallas Alcaide (2009).

16 Una visión más completa de las barreras internas exigiría tomar en consideración determinados comportamientos y actitudes del entorno familiar (ver A. García lizana y C. CAZAllas AlCaide (2009).

17 Ver P. DOERINGER Y M.PIORE (1985).

18 Un aspecto a considerar, igualmente, entre las barreras de corte administrativo, es el déficit de información existente sobre las PCD. 
Por último, las barreras por actitudes de la sociedad nos llevarían a considerar los procesos discriminatorios que las PCD sufren en el entorno social, y muy en particular por parte de los demandantes de empleo, sea por la existencia de prejuicios, falta de información sobre las posibilidades de las PCD, etc. Pero además ocurre que las $\mathrm{PCD}$ podrían estar interiorizando la discriminación que reciben de su entorno, lo que contribuye, junto con otros factores, a la formación de barreras internas para los intentos individuales de entrar o mantener su posición en el puesto de trabajo ${ }^{19}$ afectando a la función de utilidad de las PCD.

La discriminación, por tanto, a juzgar por las diferentes opiniones presentadas, influye en una retracción de la demanda laboral de PCD; pero a través de un efecto indirecto influye, igualmente, sobre la función de preferencias entre renta y ocio de las PCD, lo que afectaría negativamente a la oferta laboral. Ahora bien, para ver con mayor precisión los efectos que el hecho de la discriminación tiene sobre la curva de oferta laboral, habría que estudiar los procesos psicológicos del individuo discriminado, para entender cómo se genera y modula su preferencia por la inactividad, y poder definir con mayor contundencia posibles estrategias para resolver el problema.

\subsection{La necesidad de recurrir a la Psicología}

Así las cosas, el siguiente paso lógico que la investigación requiere es dirigir la atención hacia la Psicología para completar este análisis económico.

Existen varias razones que justifican dicha necesidad. Como se dijo anteriormente, el salario de reserva se ve condicionado por las preferencias psicológicas subjetivas (junto con la existencia de rentas alternativas). De esta manera, los procesos psicológicos del individuo son claves a la hora de determinar la forma de sus curvas de indiferencia, algo que resultará de vital importancia en la decisión entre inactividad y participación laboral. Por otra parte, también se ha dicho con anterioridad que puede estar dándose la existencia de una serie de barreras al empleo que estén condicionando dichas preferencias psicológicas subjetivas, de manera que la inactividad sea el resultado lógico de la decisión individual de la PCD. Distintos autores coinciden en llamar la atención sobre la influencia de las barreras externas sobre las internas; por lo que convendría conocer los mecanismos psicológicos a través de los cuales dicha influencia se produce (como por otra parte ya se planteó $G$. Myrdal (1944), en relación con la discriminación racial en EE.UU.).

19 Ver J. Barlow, C. Wright y L. Cullen (2002), 38. 
No parece baladí, pues, que nos planteemos la necesidad de conocer dichos vínculos y de buscar una respuesta coherente en la Psicología al problema de la mayor inactividad de las PCD, de forma que el análisis económico pueda ser completado satisfactoriamente. ¿2Por qué la curva de oferta laboral del colectivo se encuentra (y permanece) tan retraída? Es la pregunta que aún queda en el aire.

No obstante, la relación entre Psicología y Economía no es, ni mucho menos, un acontecimiento nuevo, ya que podemos remontarnos al mismo Adam Smith para encontrar tales relaciones. Siguiendo a G. F. Davis, existen rudimentos de una psicología moral en La Riqueza de las Naciones, en un sentido en el que "psicología moral" coincide con psicología económica ${ }^{20}$. Sin querer entrar en la profundidad de esta cuestión, conviene recordar que la preocupación por el propio interés, motivada por tendencias psicológicas innatas y naturales, sería la explicación principal del fenómeno económico, al actuar como elemento dinamizador de la actividad individual, que conllevaría, sin embargo, beneficios sociales.

Algunos de sus sucesores más relevantes, como Menger, Marshall o Fisher, tuvieron en cuenta, igualmente, algunos factores psicológicos en su tratamiento de los fenómenos económicos ${ }^{21}$. Pero fue Keynes quien no sólo trabajó ampliamente con tales factores, sino que formuló lo que él denominó "ley psicológica fundamental" para explicar el consumo, como piedra angular de su interpretación del funcionamiento económico, aunque eso sí, no apoyándose en los avances de la Psicología, sino en nuestro conocimiento de la naturaleza humana y en los hechos detallados de la experiencia ${ }^{22}$.

No obstante, sólo ya avanzado el siglo XX podemos encontrar una preocupación explícita y sistemática por la relación de la Economía con la Psicología. Sin ánimo de querer agotar el tema, y a mero título indicativo, podemos recordar como una serie de economistas, liderados por los trabajos de Katona y Simon, comenzaron a centrarse específicamente en estos aspectos interdisciplinares, creando el armazón teórico diferenciado que formaría las bases de la $\mathrm{EdC}$, como una perspectiva diferente al análisis microeconómico tradicional. Por tanto, dado que la investigación sobre la inactividad de las PCD que nos ocupa, casa perfectamente con las características de la EdC, el siguiente paso de nuestro trabajo nos lleva a avanzar sobre el estudio de las mismas.

${ }^{20}$ G. F. DaVIS (2003), 291.

${ }^{21}$ Ver K. E.WÄRNERYD (1989).

22 J. M. KeYNES (1983), 96. 
¿En qué consiste la EdC? Ésta es, según W.F. Van Raaij (1981) el campo de conocimiento que estudia el comportamiento económico, entendiéndolo como el comportamiento de consumidores y empresarios (de los agentes económicos humanos en general) que implica decisiones económicas, así como los determinantes (factores personales, culturales, situacionales y económicos) y consecuencias de las mismas. Según H. Hosseini (2003), la EdC es, para sus defensores, una reacción a las deficiencias de la Economía convencional. En B. Gilad y S. Kaish (1986), Simon, en el prefacio, sostiene que

necesitamos aumentar y corregir el cuerpo existente de Teoría Económica clásica y neoclásica para conseguir una imagen más realista de los procesos económicos [...] La Economía del Comportamiento es el nombre que le damos a la labor investigadora que busca cubrir estas necesidades ${ }^{23}$.

De esta manera, según H. Hosseini (2003), el término EdC se remonta a los trabajos de Katona, que implementó la introducción de elementos cognoscitivos provenientes de la Psicología social para comprender el comportamiento económico (especialmente el funcionamiento macroeconómico). Considerado, por muchos, como el padre de la EdC, en su obra se critica la "ley psicológica" propuesta por Keynes, desarrollándose un modelo alternativo (K. E. Wärneryd, (1989)). De esta forma, para G. Katona, la Psicología supone los motivos, actitudes y expectativas que influencian las decisiones sobre los asuntos económicos. Según dicho autor ${ }^{24}$ la EdC considera los procesos económicos como manifestaciones del comportamiento humano y los analiza desde el punto de vista de la Psicología moderna. En la página 8 se pregunta si la Economía, como todas las Ciencias Sociales, es una parte de la Psicología. No obstante, destaca más por sus aportaciones empíricas al campo de la $\mathrm{EdC}$ que por sus contribuciones teóricas, labor donde Simon, el otro gran impulsor de esta forma de hacer Economía, tiene una mayor relevancia.

Así pues, la teoría de H. Simon (1951) se basa en el concepto de la "bounded rationality" o "racionalidad en el límite". De esta manera, se reemplaza la hipótesis de la maximización, propia de la economía convencional, por la hipótesis de satisfacción (en este sentido, tiene relación con la teoría de la discriminación estadística de Y. B.Choi (1993), resultando de gran importancia teórica para los fundamentos de la EdC, como forma de corregir la teoría neoclásica y representar la actividad económica de forma más realista. Según se dice en H. Hosseini

\footnotetext{
${ }^{23}$ B. GILAD Y S. KAISH (1986), 16.

${ }^{24} \mathrm{G}$. KATONA (1975), 3.
} 
(2003) para que se dé la "racionalidad en el límite" deben darse simultáneamente limitaciones cognitivas humanas y de la estructura ambiental del individuo. Sin intención de querer extendernos demasiado, queremos comentar por último que su teoría ha sido interpretada de forma muy distinta entre los economistas, generando una gran polémica.

Aunque autores como Akerlof, Thaler o Frank, entre otros, también podrían ser vistos como pioneros en el campo de la EdC, no podemos terminar sin nombrar muy brevemente las importantes aportaciones llevadas a cabo por los psicólogos Kahneman y Tversky en los años setenta del pasado siglo. Estos autores atrajeron la atención del mundo económico gracias a sus pioneros ensayos y experimentos psicológicos que trataban de comprobar la hipótesis de la racionalidad en Economía. Desde entonces, tal y como dicen C. Tisdell y K. Hartley (2008), muchos economistas del comportamiento han utilizado el método experimental para comprobar la capacidad de predicción de sus teorías económicas.

Por lo que respecta al estudio de los problemas laborales, parece, por todo lo dicho, ampliamente justificada la necesidad de recurrir a la Psicología, sobre todo teniendo en cuenta sus características propias y su dependencia de la conducta humana. Así se pueden señalar los trabajos de G. M. Van Veldhoven (1985), B.Bürgenmeier (1991) o E. Kirchler (1985), entre otros. Todo lo cual hace más patente la pertinencia de realizar una aproximación desde la Psicología (importando teorías provenientes de ésta para completar el análisis económico) y desde las perspectivas de la $\mathrm{EdC}$ al estudio de la inactividad entre las PCD. El interés se centra en los comportamientos de los agentes implicados (¿qué mejor forma de conocer la oferta laborale). Se utiliza un concepto de racionalidad más cercano a la satisfacción de un nivel mínimo que al de maximización (en consonancia con la teoría de la discriminación de Choi, como se ha dicho). Y, además, se hace depender las decisiones racionales humanas de la estructura ambiental y de la existencia de limitaciones cognitivas (lo que casa con ciertas barreras al empleo, tanto externas e internas, estudiadas en apartados anteriores). Por otra parte, según C. Tisdell y K. Hartley (2008), la EdC también rechaza la homogeneidad de comportamientos supuesta por la economía neoclásica. Estamos, pues, en un contexto de EdC. Por tanto, dentro del mismo, completaremos el análisis económico de las bajas tasas de actividad de las PCD interpretando, con ayuda de ciertas teorías tomadas de la Psicología, el proceso de decisión de estas personas en relación con el mercado laboral. 


\section{Procesos de estigmatización, respuestas de afrontamien- to al estrés y participación laboral de las personas con discapacidad}

Como antes se dijo, según A. Little (2007), las PCD pueden no sentirse motivadas para reincorporarse a la fuerza laboral en vista de una serie de barreras al empleo. Entre estas barreras, se han diferenciado barreras internas y externas, pudiendo existir una relación entre la barrera externa por discriminación y la barrera interna por vulnerabilidad al estrés psicológico (que, por otra parte, se presentan como las principales barreras, que hacen que existan comportamientos distintos en el mercado dual del colectivo). De esta forma, como hizo G. Myrdal. (1944), podemos preguntarnos acerca de los efectos psicológicos de la discriminación. Esto nos aproxima al concepto de "racionalidad en el límite" de Simon, que requería la presencia simultánea de limitaciones cognitivas humanas y de la estructura ambiental, pudiendo advertirse, cómo las primeras se corresponderían con las barreras internas por vulnerabilidad al estrés psicológico, y las segundas con las barreras externas por discriminación ${ }^{25}$.

Así pues, se observa como la clave de todo el análisis está en la relación entre la discriminación y el estrés psicológico. Citando de nuevo a $\mathrm{A}$. Little, la evidencia de la duración de la dependencia asociada con la inactividad podría indicar el miedo de la familia y los efectos del estigma ${ }^{26}$. Dicho miedo explicaría la actitud de sobreprotección familiar, mientras que el estigma apunta ineludiblemente a la discriminación y marginación subsiguiente desarrollada en el cuerpo social, lo que en última instancia explicaría el comportamiento familiar defensivo, como reacción ante el miedo, y haría comprensible la situación de estrés como limitación cognitiva, en la línea de Simon.

La trascendencia de tal modelo de análisis de la situación no es puramente descriptiva. Como el citado A. Little apunta:

si los servicios de empleo pretenden proporcionar una ruta viable de vuelta al empleo, la estrategia debe dirigirse al miedo [de las familias] y a los efectos del estigma, que sirven

\footnotetext{
${ }^{25}$ De acuerdo con todo ello, la eventual independencia entre oferta laboral y salario podría interpretarse como una situación extrema, cuando de la interacción entre barreras internas y externas se genera una preferencia absoluta por la no actividad, más allá del comportamiento del mercado.

${ }^{26}$ A. LITLE (2007), 43.
} 
para fortalecer estas barreras al empleo y debilitar las conexiones entre los trabajadores inactivos y el mercado de trabajo en el tiempo. ${ }^{27}$

De esta manera, conectaremos ambos elementos (discriminación y estrés) mediante los procesos de estigmatización, y explicaremos así la mayor inactividad de las PCD (una vez que hayamos introducido las respuestas de afrontamiento al estrés) ${ }^{28}$.

Comenzaremos, pues, por definir qué es un estigma. Según J. Ruiz, la psicología social usa el término "estigma" para referirse a un amplio rango de indicadores que pueden iniciar el proceso de estigmatización ${ }^{2911}$. Sin ánimo de ser exhaustivos, nos quedaremos con la definición de E. Goffman (1963) de que un estigma es un atributo especial que produce en los demás un descrédito amplio [...] relega a la persona que lo posee a un rol estigmatizado en oposición a lo normal. Sin embargo, aunque el estigma no fuese considerado origen (de acuerdo con estas definiciones), sino resultado del proceso discriminador (como bien podría también defenderse), en la práctica se establece una correspondencia inmediata entre el concepto "estigma" y el concepto "discriminación", existiendo una gran cantidad de autores que los utilizan indistintamente (pudiendo llevar a confusión a quién desconozca el tema). Por ejemplo M. L. Baldwin y S. C. Marcus, (2006) ○ T. L. Scheid, (2005), el cual expone que las actitudes estigmatizantes o discriminatorias son una de las barreras más visibles para el empleo de las personas con discapacidad intelectual. Según J. Crocker, B. Major y C. Steele (1998), existirían tres razones para estigmatizar a otros: aumentar la autoestima del individuo o del grupo estigmatizadores, justificar un sistema basado en la desigualdad (los estigmatizadores creerían que quienes sufren el estigma es porque se lo merecen) y servir de amortiguador de la ansiedad ante ciertas amenazas (por ejemplo, el miedo a la muerte).

Siguiendo a C. T. Miller y B. Major (2000), la posesión de un estigma social constituye una fuente potencial de estrés psicológico. Es decir, la existencia de actitudes discriminatorias/estigmatizantes conduce a una situación de gran estrés en los individuos que las sufren. C. T. Miller, y C. R Kaiser (2001) proponen dos

${ }^{27}$ A. LITLE, (2007), 51.

${ }^{28}$ Obviamente, ante la consideración del miedo de las familias comentado por A. LITLE, (2007), sería oportuno, en línea con lo que se concluye en A. García Lizana y C. Cazallas Alcaide (2009), p. 20, valorar la pertinencia de considerar la unidad familiar como referente explicativo del comportamiento de la oferta, y no sólo la situación personal de los individuos implicados.

${ }^{29}$ J. RUIz (2005), 2. 
fuentes de estrés derivadas del proceso de estigmatización: una sería la ambigüedad atribucional (la incertidumbre acerca de si los resultados se deben o no a la posesión del estigma) y otra la amenaza de identidad colectiva (cuando otros miembros del grupo sufrieran alguna injusticia debido a la posesión del estigma). De esta manera, hemos conseguido el objetivo que nos propusimos: conectar la barrera externa de la discriminación con la barrera interna por vulnerabilidad al estrés psicológico. Tal estrés es el que llevaría a la persona estigmatizada a rehuir el mercado laboral, modificándose, en consecuencia, su función de utilidad.

No obstante, podríamos preguntarnos: ¿están las PCD sometidas realmente a estos procesos de estigmatización? Diversos autores así lo recogen, como entre otros J. Ruiz (2005) o T. L. Scheid, (2005). Los procesos de estigmatización que sufren las PCD encuentran su mayor relevancia en el contexto del mercado laboral, en la relación de éstos con los empleadores; pero también con los propios compañeros de trabajo ${ }^{30}$. No obstante, debido al poder de decisión que tienen a la hora de contratar, parece más relevante la estigmatización llevada a cabo por el empleador, en el sentido expuesto por T. L. Scheid (2005), fenómeno que se traduce en un endurecimiento de las condiciones de demanda laboral de PCD, cuya función específica $\left(D^{\prime}\right)$ se ve desplazada hacia niveles inferiores con respecto a la general (D) (ver figura 4).

Ahora bien, si recordamos el hilo de nuestro razonamiento, la discriminación no sólo produce la retracción de la demanda laboral (como acaba de decirse), sino igualmente la de la oferta laboral, a través del estrés psicológico inducido en la persona estigmatizada. No obstante, si creemos en la libertad individual tal vez podría cuestionarse conceder tanto valor a factores exógenos (el proceso de estigmatización) sobre la capacidad de elección del individuo. Pero, en la práctica, es preciso reconocer las limitaciones cognitivas que, en la línea de Simon, determinadas circunstancias pueden introducir, como también los condicionamientos de todo tipo a que puede verse sometido el ejercicio de la voluntad.

Sea como sea, el hecho constatado es que, al menos sobre determinados individuos, tales circunstancias pueden ser observadas. Así, al menos, parece desprenderse de la última gran encuesta realizada en España sobre discapacidad, la "Encuesta de Discapacidad, Autonomía personal y situaciones de Dependencia" (EDAD, 2008), de acuerdo con la cual se detectaron 3,85 millones de personas con discapacidad; es decir, el 8,5\% de la población. De acuerdo con la explotación

30 Ver M. E. Mclaughin, M. P. Bell y D. Y. Stringer (2004). 
de los microdatos de dicha encuesta, efectuada por Cantarero, Moreno y Murillo (2011), según se recoge en la tabla 4, puede advertirse como sólo el 10,16\% de los individuos menores de 65 años buscan trabajo; que casi la cuarta parte de los que no buscan trabajo, actúan así porque piensan que es difícil encontrarlo por su discapacidad. Pero, además, entre los que trabajan, casi la décima parte se ha sentido discriminada en el trabajo por su discapacidad, y más del doble de la cifra anterior ha sentido esa discriminación en el momento de buscar empleo.

TABLA 4: Algunos resultados de la Encuesta EDAD 2008.

\begin{tabular}{|l|l|c|}
\hline \multicolumn{1}{|c|}{ Pregunta } & \multicolumn{1}{|c|}{ Respuesta } & Tasa \\
\hline $\begin{array}{l}\text { Los individuos con limitaciones meno- } \\
\text { res de 65 años: ¿́buscan trabajo? }\end{array}$ & Afirmativa & 10,16 \\
\hline $\begin{array}{l}\text { ¿Por qué creen que no encuentran } \\
\text { trabajo? }\end{array}$ & Por su discapacidad & $\begin{array}{c}43,65 \\
\text { (de ese 10,16\%) }\end{array}$ \\
\hline \multirow{2}{*}{ ¿Por qué no buscan trabajo? } & $\begin{array}{l}\text { Es difícil por la } \\
\text { discapacidad }\end{array}$ & 23,85 \\
\cline { 2 - 3 } & No puede trabajar & $50,0 \%$ \\
\hline $\begin{array}{l}\text { ¿Ha sentido discriminación en el tra- } \\
\text { bajo por su discapacidad? }\end{array}$ & Afirmativo & 9,42 \\
\hline $\begin{array}{l}\text { ¿Ha sentido discriminación a la horade } \\
\text { buscar trabajo por su discapacidad? }\end{array}$ & Afirmativo & 20,8 \\
\hline
\end{tabular}

Fuente: Cantarero, Moreno y Murillo (2011) a partir de Instituto Nacional de Estadística: EDAD 2008.

Por tanto, hay que indagar, con ayuda de la Psicología, sobre las respuestas de afrontamiento del estrés que pueden ser adoptadas por los individuos estigmatizados, y cómo las mismas pueden afectar a la oferta laboral. Máxime si tenemos en cuenta, además, como señalan Cantarero, Moreno y Murillo (2011) que de los 22795 individuos con limitaciones que contestaron el cuestionario, 4103 declararon padecer depresión.

Desde la perspectiva de la Psicología, el individuo puede sufrir estrés, pero dependiendo de cómo quiera (o pueda) afrontarlo, optará por unas decisiones u otras (consciente o inconscientemente). Compas et al. (2001) realizan una precisa clasificación de las respuestas de afrontamiento al estrés, dividiéndolas en voluntarias 
e involuntarias ${ }^{31}$. Un estudio más detallado de las diversas opciones de cada uno de los dos grupos anteriores (que no haremos aquí por no ser nuestro objetivo) nos lleva a concluir que las mismas pueden clasificarse, según su capacidad de impacto sobre la actividad laboral de los interesados, en positivas y negativas (o funcionales y disfuncionales). La gran mayoría de estas respuestas posibles de afrontamiento al estrés son de carácter negativo, afectando a la función de preferencias de los sujetos, quienes encontrarán más sólida la opción por la no actividad, tal como se ha explicado más arriba. Ello conduciría indefectiblemente a una retracción de la oferta laboral de las PCD, que pasaría de $S$ a $S^{\prime}$ (ver figura 4), lo que, también, a su vez, repercutirá en un menor volumen de empleo (aunque los efectos sobre el salario no están definidos a priori, dependiendo del desplazamiento relativo de las curvas de demanda y oferta laboral).

\section{FIGURA 4: Efectos de la discriminación y el estrés sobre el mercado laboral}

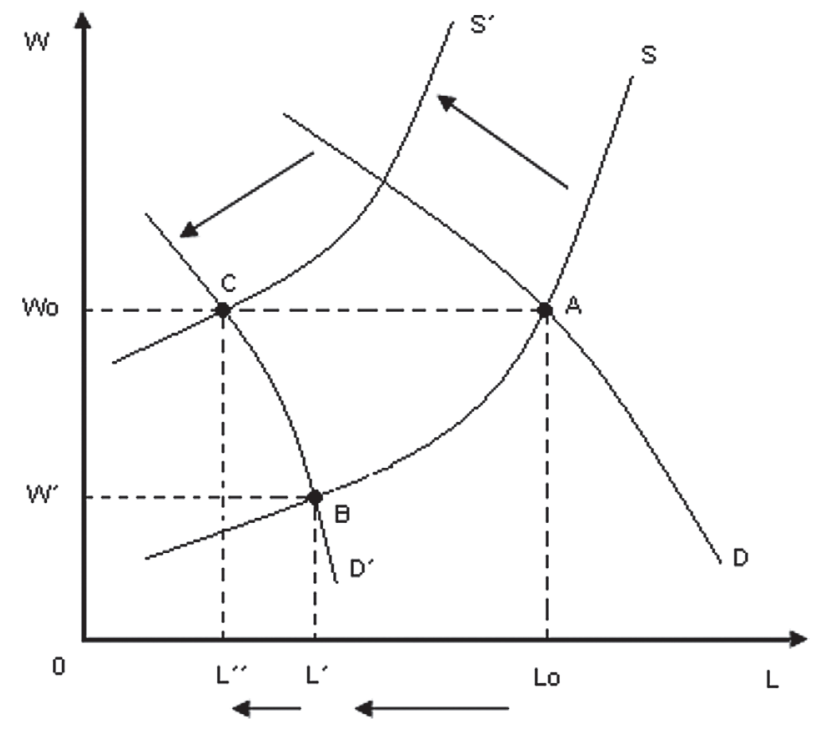

Elaboración propia.

${ }^{31}$ Ver J. RuIz (2005) 
Obviamente, las funciones indicadas interpretadas desde una óptica colectiva resultan de la agregación de las funciones individuales, las cuales serán diferentes en la medida en que lo sean los modos o la intensidad con que se afronte el estrés, por cada individuo o por subgrupos específicos que manifiestan líneas de respuesta matizadas. Bajo esta perspectiva, cuando el proceso de estigmatización sea más potente, se estará contribuyendo a la eventual ruptura de la relación entre oferta laboral y nivel de retribución, manteniéndose, en todo caso, un nivel determinado de oferta por parte de aquel grupo de individuos para los que, posiblemente por la existencia de otros mecanismos de compensación, la integración laboral es positiva por sí misma, con independencia de la retribución salarial (ver figura 5). Si pensamos en esto, la retracción de la oferta laboral vendría de la mayoritaria presencia de respuestas de afrontamiento negativas. Por otra parte, si nos decantamos por pensar que las barreras al empleo están condicionando la forma de las curvas de indiferencia del individuo (sin llegar a romperse la relación entre oferta laboral y nivel salarial), la inactividad vendría de una mayor presencia de respuestas de afrontamiento negativas, que se corresponderían con unas curvas de indiferencia más rígidas (con todas las consecuencias que esto implicaba, de posibles subgrupos dentro del mercado secundario, etc., anteriormente vistas).

\section{FIGURA 5: Independencia entre oferta laboral y nivel salarial}

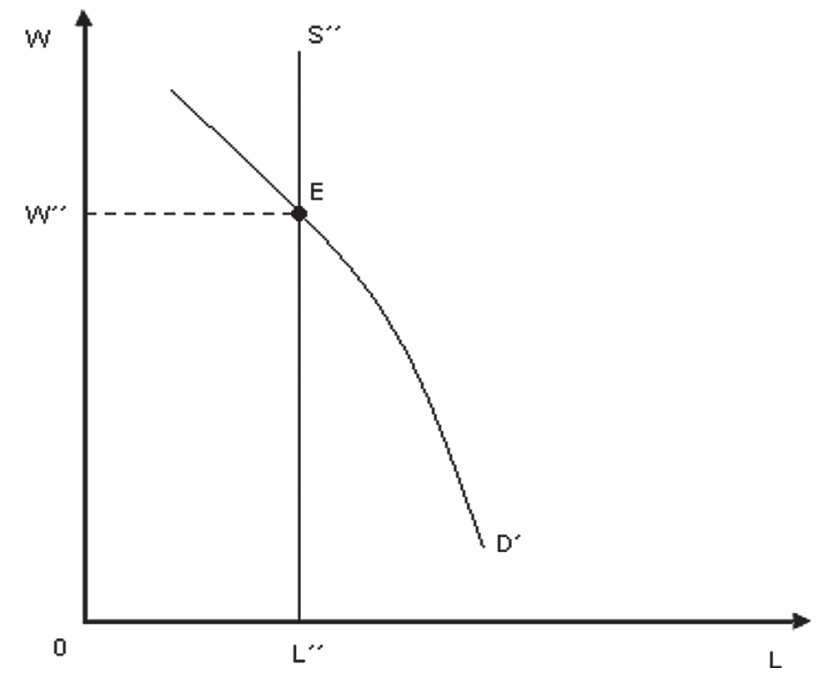

Elaboración propia. 


\section{Algunas aplicaciones de política económica}

Como muestra la evidencia empírica, los extraordinarios esfuerzos realizados en nuestro país (como en otros de nuestro entorno) al respecto, no se han traducido en resultados significativos, persistiendo la misma panorámica laboral con escasas variaciones con el paso de los años. Por ejemplo, a pesar de los incentivos fiscales y de las cuotas obligatorias de contratación, el hecho evidente es el reducido empleo de las PCD, pues según el Consejo Económico y Social en 2009 a pesar de haberse incrementado en los últimos años el número de actuaciones sancionadoras de la Inspección de Trabajo y Seguridad Social, asumiendo las empresas el pago de la sanción como opción preferible a la contratación de PCD. Por otra parte, según H. Benítez-Silva

los tradicionales modelos de análisis del problema, reducidos y de base empírica, no están bien equipados para proporcionar recomendaciones políticas útiles a los responsables políticos y legisladores, dada la miríada de complejidades relacionadas con la comprensión de cómo cambios en los programas afectarán a los comportamientos individuales ${ }^{32}$.

Lo que nos remite indefectiblemente a los procesos de estigmatización y al estrés asociado que marcan a las PCD.

Dado que no es el objetivo fundamental de este artículo, sin ánimo de ser exhaustivos sólo apuntaremos algunas conclusiones prácticas que se desprenden del análisis efectuado, y que debieran ser tenidas en cuenta por los responsables de las administraciones públicas y de la sociedad civil.

De acuerdo con lo planteado, podría apuntarse a la reducción de las rentas no salariales de carácter público (prestaciones sociales), como un modo simple, fácil y directo de rebajar el salario de reserva. No obstante, es evidente que desde una óptica social no parece recomendable. Pero tampoco se orienta hacia el problema focal: las preferencias de la población con discapacidad, que están condicionadas por las peculiaridades de los procesos de discriminación existentes y por los modos de afrontar el estrés inducido por tales procesos. Deberían atenderse diversas líneas de conducta política, sin perder de vista la importancia de la participación de los interesados y de sus organizaciones como elemento que contribuye a mejorar las actuaciones concretas y la integración general:

32 H. BeníteZ-SILVA (2009) 180. 
a) Abordar un tratamiento desagregado del problema, identificando los diversos modelos de comportamiento en función de la segmentación del grupo, lo que requiere mejorar el conocimiento de la situación como soporte del diseño y aplicación de las iniciativas políticas.

b) Reforzar las políticas orientadas a reducir los procesos de discriminación/estigmatización, mejorando los sistemas de información sobre las PCD, las políticas de sensibilización y la adaptación de los lugares de trabajo, haciendo visibles los beneficios que todo ello puede reportar también al conjunto de los trabajadores y a la sociedad en general, y no sólo a las PCD.

c) Revisar la política de cuotas, centros especiales de empleo e incentivos fiscales, no sólo por la reducida efectividad demostrada (en particular en el caso de las cuotas), sino por convertirse en elementos jurídicos que contribuyen a hacer más visible el estigma ${ }^{33}$. En todo caso deberían instrumentarse como parte de las políticas de sensibilización (apartado b) y de formación de capital humano (apartado d).

d) Reforzar la capacidad de los individuos para afrontar positivamente el estrés generado por el estigma, aplicando refuerzos educativos y psicológicos específicamente diseñados, mediante personal especialmente entrenado, con una visión clara de los problemas, de manera que se refuerce la autoestima y se ofrezcan recursos personales para una adecuada percepción de la realidad y la adopción de decisiones. La política de inversión en capital humano debe ser mirada con especial atención; no tanto porque permita acceder a puestos mejor remunerados, como por la seguridad y apoyo a la propia personalidad.

e) Fomentar el autoempleo, lo que requiere formación de capital humano, asesoramiento técnico, políticas de acompañamiento y apoyo financiero aplicado con parsimonia y fomentando el sentido de la responsabilidad. La subvención, en cuanto tal, puede ser también un modo de reforzar el estigma, si no está adecuadamente orientada.

f) Adecuado seguimiento y evaluación de las políticas aplicadas, atendiendo a los resultados obtenidos y no tanto a los medios empleados o a las oportunidades concedidas.

${ }^{33}$ Ver T. Besley y S.Coate (1992); y G. Demuinnck y C. Le Clainche (2009). 


\section{Conclusiones}

Reconociendo la débil integración laboral de las PCD, tras considerar las insuficiencias de las aproximaciones neoclásicas e institucionalistas de manera aislada para explicar satisfactoriamente la situación, se ha constatado la utilidad de tomar en cuenta la EdC, incorporando elementos tomados de la Psicología con el fin de comprender de manera más completa las pautas de decisión de las PCD, con respecto al mercado laboral, enriqueciendo así las aproximaciones convencionales.

De esta manera, se desprende la importancia de los procesos de estigmatización social en la medida en que inciden sobre la población estigmatizada, generando una situación de estrés psicológico que presiona sobre las pautas de comportamiento de los individuos, modificando su función de utilidad, hasta el punto de rehuir la incorporación al mercado laboral, desplazando de este modo la función de oferta laboral de las PCD y haciéndola más rígida, pudiendo llegar a romperse la relación entre oferta laboral y retribución salarial en situaciones límite. Como hemos visto, las respuestas a dicho estrés serán fundamentales, y condicionarán la participación, o no, en el mercado laboral de las PCD (con independencia, claro está, de las situaciones en que tal opción sea imposible por razones estrictamente médicas).

Por todo ello, la percepción de tal secuencia de comportamientos sugiere la necesidad de revisar las políticas y prácticas habitualmente aplicadas para conseguir resultados más sólidos que los obtenidos hasta el presente en el ámbito de la integración laboral de las PCD. No obstante, las conclusiones presentadas en este trabajo plantean la necesidad de profundizar en la contrastación empírica específicamente dirigida a validar los resultados obtenidos; así como las circunstancias que rodean las respuestas de afrontamiento positivas y negativas.

\section{Bibliografía}

Albarrán, I., Alonso, P. y Fajardo, M. A. (2009) "Discapacidad, dependencia y empleo", en P. Alonso González, D. Cantarero Prieto, J. Núñez Velázquez y M. Pascual Sáez (eds.) (2009) Ensayos sobre Economía, Discapacidad y Empleo, Madrid, Delta.

BALDWIN, M. L. y MARCUS, S. C. (2006) "Perceived and measured stigma among workers with serious mental illness": Psychiatric Services, 57(3), 388-392. 
BARLOW, J. H. y HARRISON, K. (1996) "Focusing on empowerment: facilitating self help in young people with arthritis through a disability organization": Disability and Society, 11, 539-551.

Barlow, J. H. (1998) "Arthritis", en M. JOHnston y D. JOHnStON (eds.) (1998) Health Psychology, Comprehensive Clinical Psychology Series, vol. 8, Amsterdam, Elsevier, 427-443.

Barlow, J., WRIGHT, C. y CULlen, L. (2002) "A job-seeking self-efficacy scale for people with physical disabilities: Preliminary developmentand psychometric testing": British Journal of Guidance and Counselling, 30(1), 37-53.

BARNES, C. Y MeRCER, G. (2005) "Disability, work and welfare: challenging the social exclusion of disabled people": Work, Employment and Society, 19(3), 527-545.

BeNíteZ-SILVA, H. (2009) "Disability, social insurance and labor force attachment", en P. Alonso González, D. Cantarero Prieto, J. Núñez Velázquez y M. Pascual Sáez (eds.) (2009) Ensayos sobre Economía, Discapacidad y Empleo, Madrid, Delta.

BESLEY, T. y CoATE, S. (1992) "Understanding Welfare Stigma: Taxpayer Resentment and Statistical Discrimination": Journal of Public Economics, 48, 165-183.

Bürgenmeier, B. (1991) "The Labor Market in a Socio-Economic Perspective": The Journal of Socio-Economics, 20(4), 297-312.

Calderón Vázquez, F. J., Pérez Moreno, S. y Cruz Morato, M. A. (2010), "Aproximación al fenómeno migratorio desde la óptica del análisis económico": Anales de Economía Aplicada (International Conference on Applied Economics Asepelt 2010), 24, 535-554.

Cantarero, D., Moreno, P. y Murilo, C. (2011) "La depresión como factor limitante en las actividades diarias y su efecto en la permanencia en el mercado de trabajo. Estudio empírico con la EDAD (2008)": Anales de Economía Aplicada, 25.

CHOI, Y. B. (1993) Paradigms and Conventions: Uncertainty, Decision Making and Entrepreneurship, Ann Arbor (MI), University of Michigan.

Compas, B. E., Connor-Smith, J. K., Saltzman, H., Thomsen, A. H. y Wadsworth, M. E. (2001) "Coping with stress during childhood and adolescence: Problems, progress and potential in theory and research": Psychological Bulletin, 127(1), 87-127. 
Crocker, J., Major, B. y Steele, C. (1998) "Social stigma", en D.Gilbert, S.T. Fiske y G. LINDZEY (eds.) (41998) Handbook of social psychology, Boston, McGraw Hill, vol. 2, 504-553.

Cruz Morato, M. A. y García lizana, A. (2011) "La participación de las personas con discapacidad en el mercado laboral: Una aproximación desde la Economía del Comportamiento": Anales de Economía Aplicada 25.

DavIS, G. F. (2003) "Philosophical Psychology and Economic Psychology in David Hume and Adam Smith": History of Political Economy, 35(2), 269-304.

Demuinek, G. y Le Clainche, C. (2009) "Disability and discrimination in access to employment: what the people think about positive discrimination and integration", en P. Alonso González, D. Cantarero Prieto, J. Núñez Velázquez y M. Pascual Sáez (eds.) (2009) Ensayos sobre Economía, Discapacidad y Empleo, Madrid, Delta.

Doeringer, P. y PIORE, M. (1985) Mercados internos de trabajo y análisis laboral. Madrid, Ministerio de Trabajo y Seguridad Social.

EdWARDS, J. y BoXALL, K. (2010) "Adults with cystic fibrosis and barriers to employment": Disability and Society, 25(4), 441-453.

Gannon, B. y Nolan, B. (2004) "Disability and Labour Market Participation in Ireland": Economic and Social Review, 35(2), 135-155.

Gannon, B. y Nolan, B. (2007) "Transitions in disability and work": Estudios de Economía Aplicada, 25(2), 447-472.

García Lizana, A. y Cazallas Alcaide, C. (2009) "Teorías del mercado de trabajo de PCD", en P. Alonso González, D. Cantarero Prieto, J. Núñez Velázquez y M. Pascual Sáez (eds.) (2009) Ensayos sobre Economía, Discapacidad y Empleo, Madrid, Delta.

García lizana, A. y Fajardo Caldera, M. A. (coords.) (2008) "Estudio de investigación sobre Economía, Discapacidad y Empleo desde la perspectiva de la Economía Aplicada. Investigación para la Fundación ONCE" (policopiado).

García Serrano, C. y Malo, M.A. (2002) "Discapacidad y mercado de trabajo en la Unión Europea": Cuadernos Aragoneses de Economía, 12(2), 237-255. 
GILAD, B. y KAISH, S. (eds.) (1986) Handbook of Behavioral Economics (vv. A y B), Londres, JAI Press Inc.

Goffman, E. (1963) Stigma: Notes on the management of spoiled identity, Englewood Ciffs (NJ), Prentice-Hall.

HAGNER, D. (2000) "Primary and Secondary Labor Markets: Implications for Vocational Rehabilitation": Rehabilitation Counseling Bulletin, 44(1), 22-29.

HIRST, M. y BALDWIN, S. (1994) Unequal Opportunities: Growing Up Disabled, Londres, Social Policy Research Unit.

HosselNI, H. (2003) "The arrival of behavioral economics: from Michigan, or the Carnegie School in the 1950s and the early 1960s?": Journal of Socio-Economics $32,391-409$

Instituto Nacional de Estadística (2002) Encuesta sobre Discapacidades. Deficiencias y Estados de la Salud 1999. Resultados detallados.

InStiTUto NaCIONAL DE Estadística (2002) Las personas con discapacidad y sus relaciones y su relación con el empleo: Encuesta de Población Activa del segundo trimestre de 2002.

Instituto Nacional de Estadística (2008) Encuesta de Discapacidad, Autonomía personal y situaciones de Dependencia. Resultados detallados.

Instituto Nacional de Estadística (2011), "Encuesta de Población Activa. Datos del tercer trimestre de 2010". http://www.ine.es/jaxiBD/menu. do?L=0\&divi=EPA\&his=1\&type=db [Última consulta: 17 de marzo de 2011]

INEM (2006-2008). Estadísticas de contratos. Serie de datos mensuales. En: http://www. sepe.es/contenidos/cifras/datos estadisticos/contratos/datos/estadisticas nuevas.html [Última consulta: 18 de julio de 2010]

Katona, G. (1975) Psychological Economics, Amsterdam, Elsevier.

KeYNES, J. M. (1983) The General Theory of Employment, Interest and Money [1936], Cambridge (R. U.), Macmillan y Cambridge University.

KIRCHIER, E. (1985) "Job loss and mood": Journal of Economic Psychology, 6, 9-25. 
Kroll, T. Y PeAKE, S. (1996) Employment Situation of Young Adults in Scandinavia, (Research Report), Oslo, Norwegian Arthritis Organisation (NRF).

LITLE, A. (2007) "Inactivity and Labour Market Attachment in Britain": Scottish Journal of Political Economy, 54(1), 19-54.

Mcconnell, C., Brue, S. y MAcPherson, D. (2003) Economía Laboral, Madrid, McGraw-Hill.

Mclaughun, M. E., Bell, M. P. y Stringer, D. Y. (2004) "Stigma and acceptance of persons with disabilities: Understudied aspects of workforce diversity": Group and Organization Management, 26(3), 302-333.

Miller, C. T. y MAJOR, B. (2000) "Coping with stigma and prejudice", en T. F. HeATHERTON, R. R. KLECK, M. R. HEBL y J. G. HuLL (eds.) (2000), The social psychology of stigma, Nueva York, Guilford, 243-272.

MILLE, C. T. y KAISER, C. R. (2001) "A theoretical perspective on coping with stigma": Journal of Social Issues, 57, 73-92.

Myrdal, G. (1944) An American Dilemma, Nueva York, McGraw-Hill.

OCDE (2007) Sickness, Disability and Work: Breaking the Barriers. Vol. 3: Denmark, Finland, Ireland and the Netherlands, en: http://www.oecd.org/documen $\mathrm{t} / 62 / 0,3343$,en 26493474741662270111 l 1,00.html [Última consulta: julio de 2009].

Phelps, E. S. (1972), "The statistical theory of racis and sexs": American Economic Review (septiembre), 659-661.

RodríGuez, J. A. y DelGADO, J. (2009) "La atención a la integración laboral de las personas discapacitadas en la Unión Europea": Revista de Fomento Social, 64, 103-130.

Ruiz, J. (2005) "La Discapacidad como estigma: un análisis psicosocial del afrontamiento del desempleo de las PCD física": Revista REDSI (Red Social Interactiva) (enero).

SCheid, T. L. (2005) "Stigma as a barrier to employment: Mental disability and the Americans with Disabilities Act": International Journal of Law and Psychiatry, 28(6), 670-690. 
SIMON, H. (1951) Models of Man, New York, Wiley.

SMITH, A. [1776] (1989) An inquiry into the nature and causes of wealth of nations, Chicago, Encyclopaedia Britannica.

Tisdell, C. y HartLey, K. (2008) Microeconomic Policy. A new perspective, Cheltenham (UK), Edward Elgar.

Van RaAiJ, W. F. (1981) "Economic Psychology": Journal of Economic Psychology, $1,1-24$.

Van Veldhoven, G. M. (1985) "Unemployment and Economic Psychology: An Introduction": Journal of Economic Psychology, 6, 1-8.

Vicente, M. R. y López, A. J. (2007) "El empleo de las PCD en la sociedad de la información: desafíos para los nuevos estados miembros": Estudios de Economía Aplicada, 25(2), 429-446.

WÄrNERYD, K. E. (1989) "On the Psychology of Saving: an essay on Economic Behavior": Journal of Economic Psychology, 10, 515-541. 